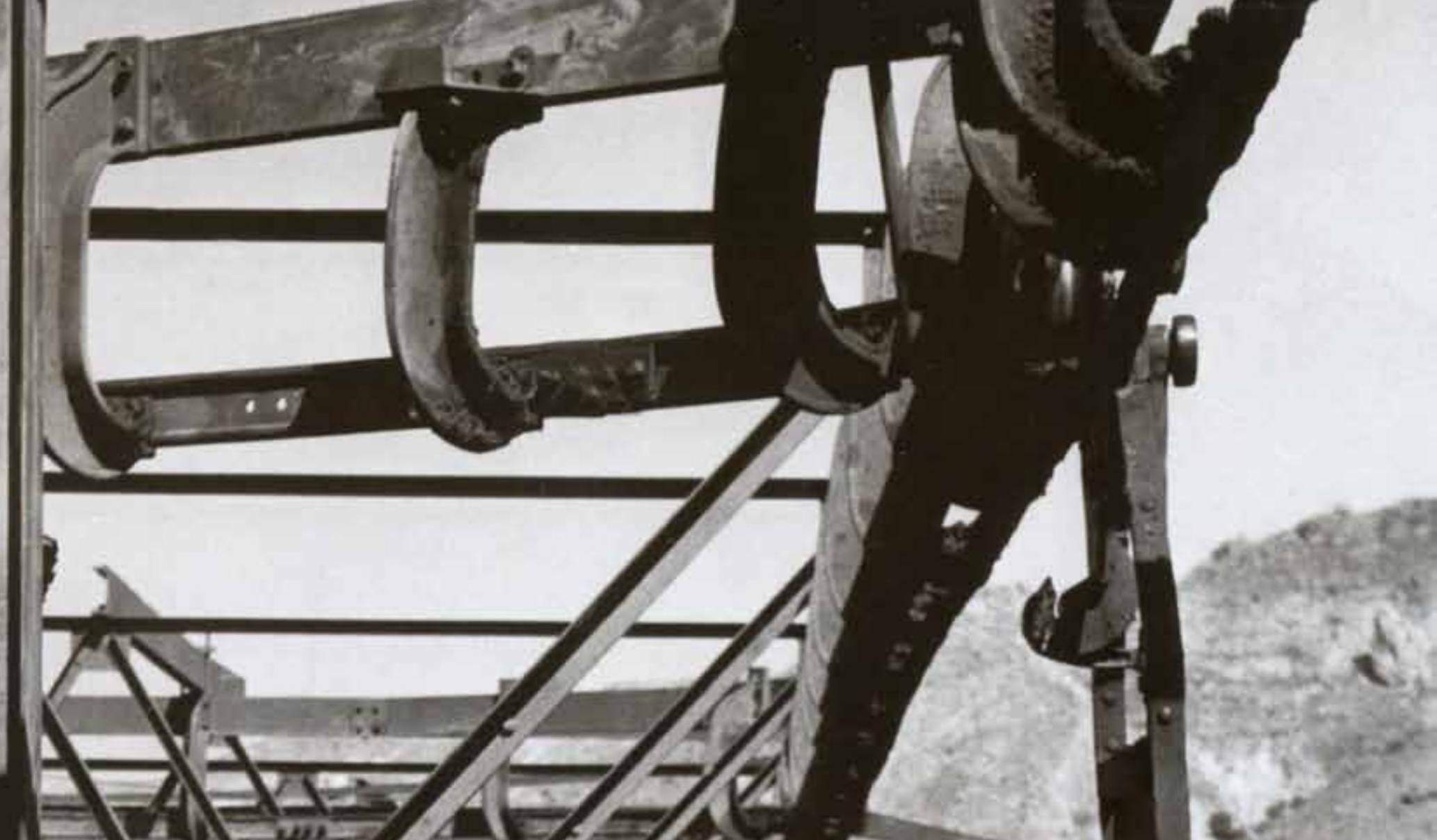

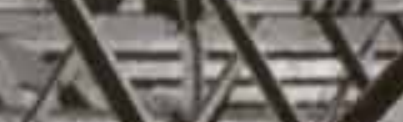

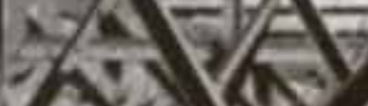
$4 \times 260$

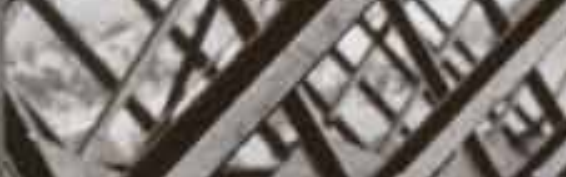

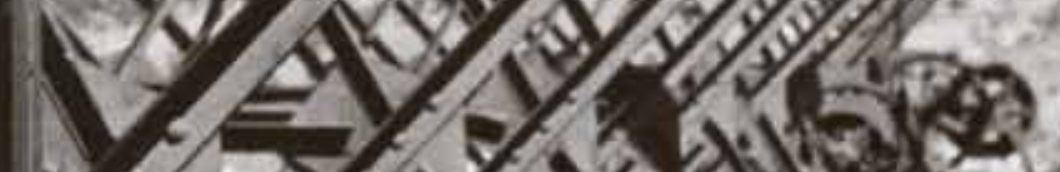

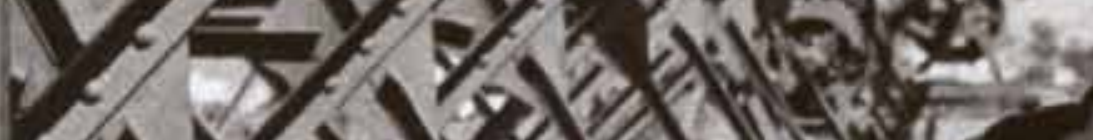
(1)

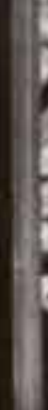

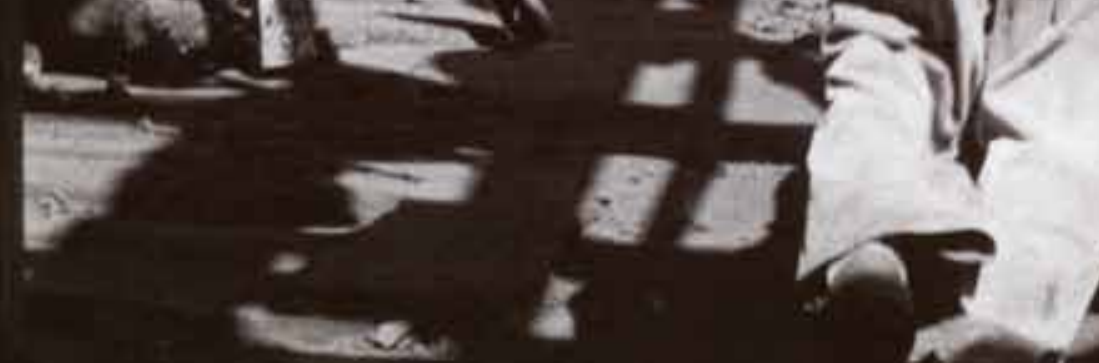




\section{Itinerario histórico por la minería del valle del Almanzora}

Juan Torreblanca Martínez, técnico en gestión cultural, Diputación Provincial de Almería
El valle del Almanzora y la sierra de Filabres han sido desde el punto de vista histórico una región minera. Este pasado minero es, seguramente, uno de sus más extraordinarios valores patrimoniales y signos de identidad colectiva. La antigüedad e importancia de estas diversas explotaciones mineras han conferido a la minería el carácter de una actividad de gran tradición en la comarca: hierro, plomo, carbón, plata, oro, mármol, mercurio, cobre, yeso, talco, etc. son entre otros los minerales y rocas beneficiadas históricamente en un proceso permanente de activaciones y desactivaciones, llegando hasta la gravisima crisis que padece el sector en la actualidad. Un antiguo adagio del país confirma y enfatiza con rotundidad la vinculación que ha existido en el valle entre riqueza y mineria: Del Almanzora, la cabecera y la cola, en clara alusión a los enclaves mineros que la geología hizo posible en los yacimientos de hierro y mármol de la sierra de Filabres y en el plomo y plata de Almagrera y Herrerías.

Los vestigios de actividad minera datan de época neolítica, desde el descubrimiento mismo de los metales, pudiéndose decir que los habitantes del Almanzora pasan por ser considerados como los primeros metalúrgicos de la Península. Pero no es sino hasta la llegada del ferrocarril a la zona en la última década del siglo XIX cuando estas grandes riquezas del subsuelo se ponen en explotación. En este intervalo de tiempo, entre la prehistoria y la Revolución Industrial, la mineria del valle del Almanzora va a tener algunos momentos de esplendor, especialmente en época romana o en el Reino Nazari de Granada, en donde para el caso del hierro se localiza en Bacares una de las dos fábricas de armas de los nazaritas, o la utilización del mármol de Macael para la realización de suntuosas columnas o las dos losas llamadas las Dos Hermanas en el palacio de la Alhambra. Episodios éstos en los que a pesar de su importancia no son sino manifestaciones esporádicas en comparación con la intensa actividad de la época romana.

Descargando un balde en el cargadero de Los Canos. Hacia 1950-1960. Foto: A D. Dons. Col. Emilio Herrero Pérez. Fuente: Las Menas. Una mirada al mundo minero 11915-1968). Albolote, Granada: Arráez Ed., Diputación Provincial de Almería, 2011
La singular percepción de dos testigos de excepción que visitan la comarca a principios y finales del siglo XIX, Simón de Rojas y Gustavo Gillman, nos va a servir de guía para mostrar a través de sus documentados testimonios la importancia estratégica que la minería va a jugar en el devenir histórico de esta comarca.

El diario del viaje científico que Simón de Rojas Clemente Rubio realiza a Andalucia entre 1804 y 1809 recoge una amplísima información de la geología y minería de las zonas que visita en su hoja de ruta. El valle del Almanzora lo visita en varias ocasiones: la primera, viniendo desde Baza, pasa por Serón, Bacares, Bayarque, Sufli, Macael y Somontín, es decir, el alto Almanzora; en otro viaje penetra en el valle a través de Oria; y, en el último, a través de Carboneras, Vera, Zurgena y Arboleas. Gracias al espíritu reformista y sensible de este incansable viajero, conocemos las imágenes de un mundo que destila cotidianidad y que apenas había cambiado en los últimos siglos, aunque en algunos lugares se reconocen signos de progreso. Esos aspectos de dinamismo los encuentra precisamente en los enclaves donde se desarrolla una minería preindustrial, limitándose en la mayor parte de los casos a suministrar mineral de hierro a las ferrerías instaladas en el país, especialmente las de Serón y Bacares, y en menor medida la de Cóbdar; en las canteras de mármol de Macael, Albanchez, Chercos y Cóbdar, en las minas de esteatita de Somontín o en los bancos de yeso de algunos pueblos, especialmente Bayarque y Sufli.

Los comentarios que realiza sobre la actividad minera son indicativos de la riqueza legendaria y prodigiosa de sus minerales y rocas: "La jurisdicción de Bacares rebosa hierro y está cubierta de escorias por todas partes... La Herreria de Serón tiene una fragua con bomba, da cada año seis mil arrobas de hierro que se consumen en los pueblos de ocho leguas alrededor, sin que quede nada para Lorca y Granada, que lo piden por su excelente calidad. Si la fábrica ésta cae del todo algún día será por la escasez de leña y de astiles para el machete a falta de buenas encinas, no por falta de mena ni de actividad e inteligencia y aún de economía de la fábrica que dirige y ha perfeccionado mucho, 


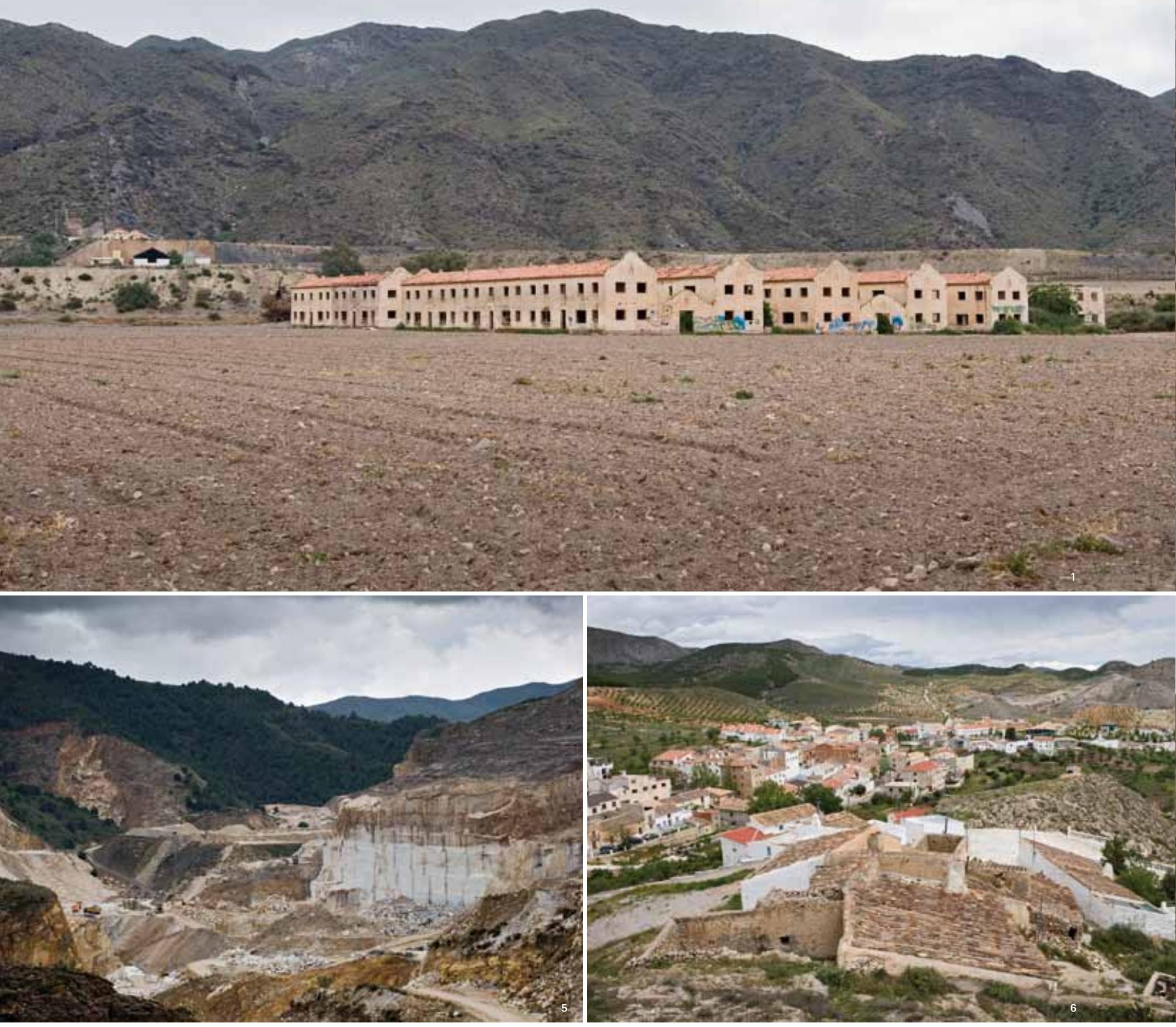

1. Poblado minero El Arteal

2. Mina del Pilar de Jaravia (Pulpí)

3. Suflí

4. Poblado minero Las Menas de Serón

5. Mirador de Las Canteras (Macael)

6. Oria

7. Somontín

气 8. Poblado minero Las Menas de Serón

Fotos: Todas las imágenes que ilustran este artículo pertenecen al Fondo

Gráfico IAPH (luan Carlos Cazalla) 


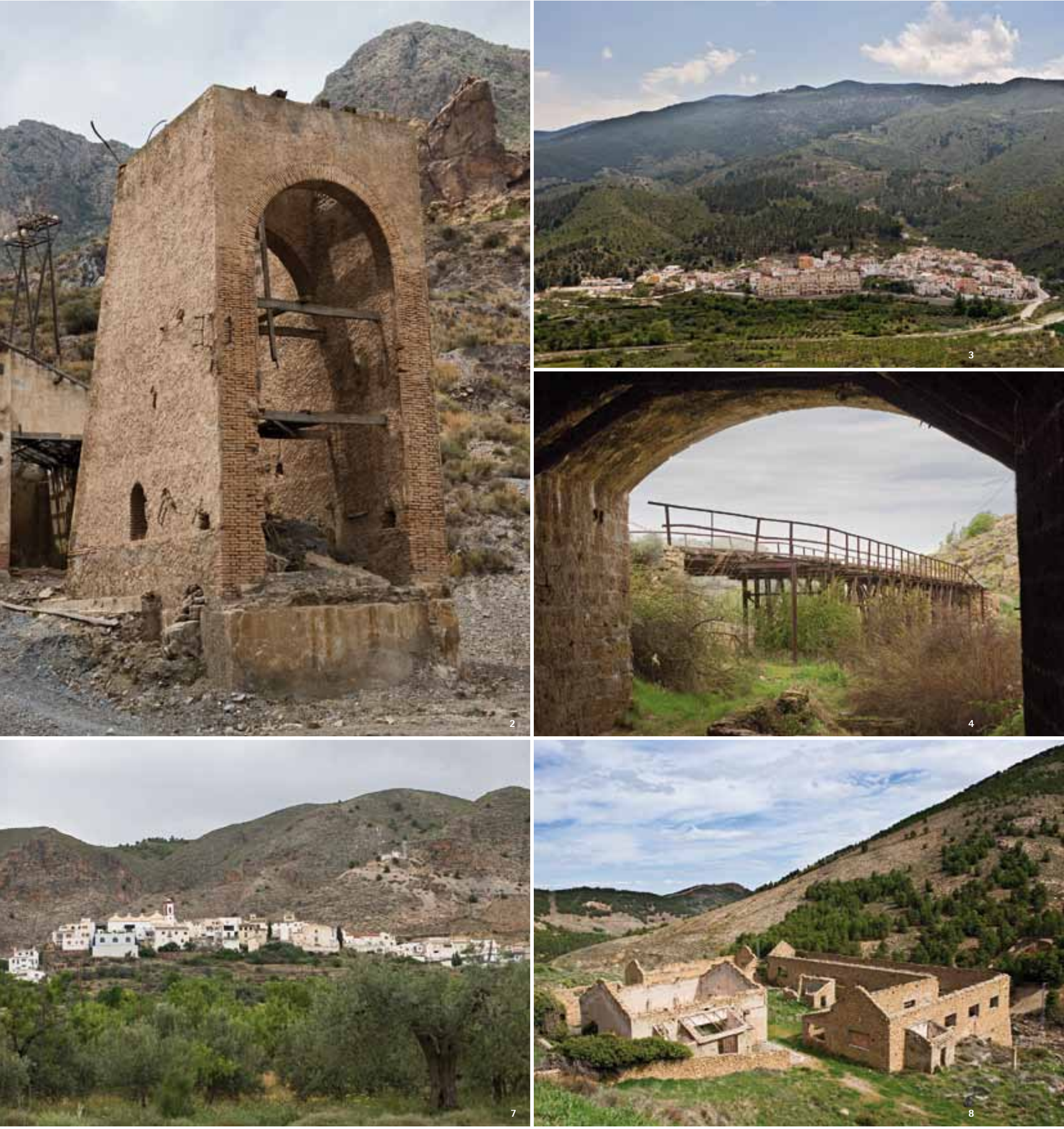




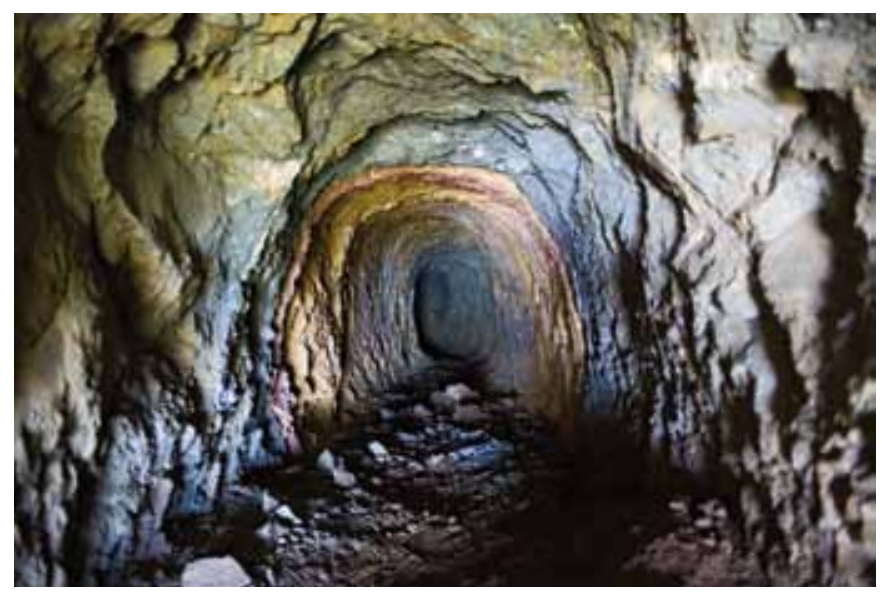

Mina de Bédar

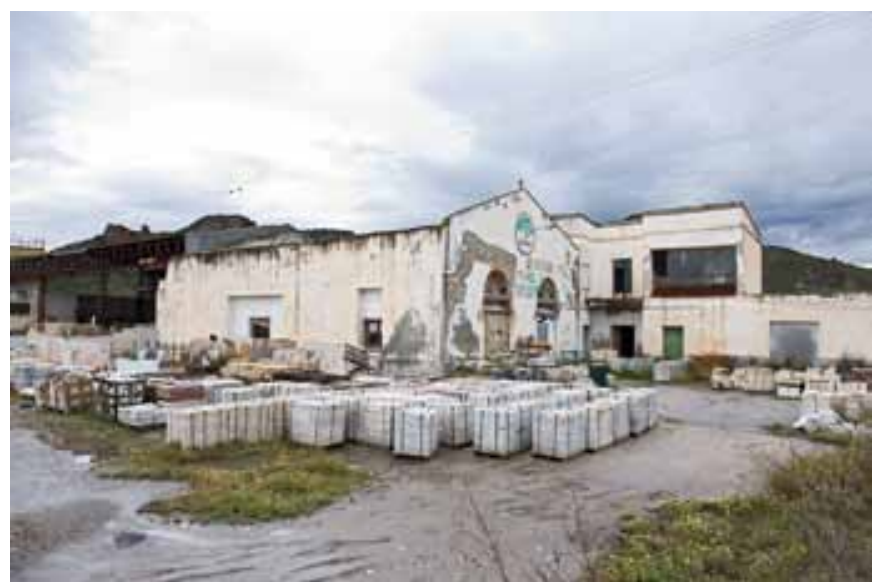

Fábrica de mármol en Cantoria

por cuenta del conde de Miranda, don Martín Garnica. Lo que hace famoso a Macael es su mármol, blanco y purísimo, el único que se labra en España... En Sufli tienen inmediato al pueblo una cantera de yeso, la más preciosa que hasta aqui he visto..."

Durante los largos periodos de inactividad minera, la comarca vivía de los recursos agrarios y ganaderos, dentro de los márgenes de una economía de subsistencia de base agraria, al tiempo que se detecta una fuerte y crecida emigración histórica. "Los pobres habitantes del Río Almanzora, estrechados entre éste y la Sierra, con muy poco terreno cultivable y ellos sin industria, salen no por actividad, sino aquejados por el hambre, a ganar su vida por toda la Andalucia y pasan fuera de su casa la mayor parte del año. Espadan lino en la Hoya de Baza, van a cavar viñas y a arar a los Reinos de Córdoba y Jaén, a coger la aceituna y a segar aquella en el Reino de Córdoba principalmente y a segar, los más en el Reino de Sevilla". Esto sucedia en todos los pueblos, aunque específicamente lo señala en el caso de Macael, lugar donde indicaba que casi todos sus vecinos pasaban más de seis meses fuera de sus casas... "Los del Río Almanzora, Sierra de Filabres y Alpujarras, son los jornaleros universales".

Unas décadas después la situación en el valle era aún peor que la descrita por el naturalista Simón de Rojas. Algunas de sus predicciones se habian cumplido, las ferrerias de Bacares y de Serón habian parado por la escasez de leña con las que alimentar a las forjas catalanas de estas fábricas. Este fenómeno fue detectado por los coetáneos que no dudaron en considerar que el alto consumo de combustibles de las ferrerias las convirtió en uno de los principales agentes desforestadores. Pascual Madoz informaba en su diccionario que los bosques de Bayarque, Tíjola y Bacares habian sido destruidos por el consumo de carbón de las fábricas de hierro sitas en Serón y Bacares. Más de 25 millones de árboles habian desaparecido, dejando esquilmada de cobertera vegetal a la sierra de Filabres, por causa de las roturaciones, las talas y las explotaciones de espartos y barrillas.

A mediados de la década del siglo XIX se instaló una fábrica de nitro en el entorno del río Herrerias, en Serón, para beneficiar el mineral extraído de las cuevas de La Sarna, Las Narices y La Sima, aunque el mineral extraído fue tan escaso que no tuvo más remedio que cerrar, dando por tierra a una experiencia tan escasamente exitosa.

\section{LA REACTIVACIÓN MINERA DEL VALLE DEL ALMANZORA}

El ambiente socioeconómico de esta época nos muestra a un mundo detenido, estancado por una rutina de siglos y de ausencias de progreso. Ese letargo y monotonía sociocultural van a ser interrumpidos bruscamente con el ferrocarril que introduce los primeros sintomas de modernidad y de cambio. Un testigo excepcional de la ruptura de este mundo inalterable va a ser Gustavo Gillman. En él se conjugan la faceta del viajero romántico fascinado por aquel mundo inalterable que el ferrocarril y la mina va a poner en contradicción; y por otro lado representa la imagen del ingeniero visionario que cree en las fabulosas riquezas mineras de la zona y soluciona los problemas de su transporte -en contra de todas las opiniones técnicas y económicas hasta ahora mantenidas, por las dificultades que representaba la explotación minera de la sierra de Filabresdando viabilidad a un negocio minero de proporciones extraordinarias que termina por revolucionar aquel mundo inmutable. El legado fotográfico del ingeniero director del ferrocarril The Greatt Southern of Spain Railway Company Limited (ferrocarril Lorca-Baza) es quizás el testimonio gráfico conocido más extraordinario de la espectacular mutación ocurrida en el valle del Almanzora con la llegada del ferrocarril. La impresionante labor que Gillman supo imprimir al sector minero de la comarca para rentabilizar económicamente al ferrocarril constituirá el hito simbólico del paso de un mundo a otro.

En el último quinquenio de 1890 el negocio minero de la sierra de Filabres se activa de una manera vertiginosa, venía a coincidir esta etapa con la puesta en funcionamiento del ferrocarril Lorca-Baza. La compañía del ferrocarril como opción preferencial que hiciera rentable su explotación tenía puestos sus ojos en las minas de hierro de la sierra de Filabres. Su director, Gustavo Gillman, se ocupaba con predilección de estos negocios 
mineros, para lo cual había constituido una compañia minera, la The Bacares Iron Ore Mines Limited Company, y planificaba tres cables aéreos que unieran las minas con la estación de Serón, llevando a cabo dos de ellos, los del Manzano y Cortijuelo. A partir de los proyectos y empresas de Gillman se activa una serie de iniciativas que tienen como nexo la mineria y el transporte de minerales por el ferrocarril, de esta manera varias compañias extranjeras explotan los yacimientos de la cuenca de Serón-Bacares: Mines et Chemin de Fer Bacares-Almería et Extensions, W. H. Muller y Cía., que en 1911 construye otro cable aéreo propio, el de Los Canos, y la compañía minera Cabarga San Miguel que se mantiene explotando el sector hasta su cierre, ocurrido en 1968. Durante este periodo se extrajeron unos 25 millones de toneladas. En el corto espacio de una década el ferrocarril de Lorca-Baza se había convertido en un ferrocarril minero, y el alto Almanzora se habia transformado en uno de los distritos mineros más importantes de Andalucia. Hasta cinco cables aéreos vaciaban mineral para ser transportados por el ferrocarril hasta el puerto del Hornillo en Águilas. La nueva imagen de la cuenca no puede ser más evidente.

Por su gran poder organizador, debido a los cuantiosos insumos requeridos y a sus efectos multiplicadores, la actividad minera crea y organiza espacios económicos. Estos enclaves -sociales, económicos y culturales- se van a constituir en las antiguas zonas de mineria preindustrial: el hierro y el mármol de la vertiente norte de la sierra de Filabres, el oro de las arenas aluviales de Armuña del Almanzora y de Serón, el cobre de la Cueva de la Paloma en Bayarque y de Las Cocotas en Tíjola, el mercurio en Bayarque, el carbón en Albanchez, el talco en Somontín y en Lúcar, el wolfranio en Cóbdar o la explotación de canteras de yeso en Zurgena, Bayarque, Serón y especialmente en Sufli. Aunque ahora van a ser trabajadas más intensamente y con nuevos métodos de explotación, a pesar de ello siguen detectándose la pervivencia de antiguos sistemas laborales con los nuevos procedimientos e innovaciones técnicas.

La minería transformó con una rapidez vertiginosa la estructura económica y ocupacional de la zona. Los cambios fueron espectaculares, tanto desde el punto de vista de la estructura productiva como de sus visibles efectos demográficos. Sorprende comprobar la rapidez e intensidad del proceso: en el corto plazo de dos décadas una radical mutación había acontecido en la cuenca minera de Serón-Bacares. Distintos testimonios contemporáneos de la época señalan documentalmente la proporción del prodigio: planos inclinados, cables aéreos, tolvas de mineral, grandes almacenes, talleres, oficinas, hospitales, barriadas diseminadas, el ascenso y descenso de los obreros para entrar en las minas, etc. Todo un paisaje industrial que contrasta con las desoladoras descripciones de unos pocos años antes sobre un lugar donde sólo habitaban los cuervos y las águilas. Igual proceso va a ocurrir, aunque con menor intensidad, en los otros dos enclaves mineros, los talcos de Somontín y Lúcar y el mármol de Macael, Albanchez, Lijar, Cóbdar y Chercos.
La otra riqueza minera de la zona eran las canteras de mármol de Macael, cuyo material comienza a ser transportado por ferrocarril, pero que continuaba con sus problemas estructurales de producción y de transporte. Espectacular era el transporte de las grandes masas de mármol en grandes y fortísimos carros arrastrados por bueyes situados en su parte delantera y trasera, para poder bajar el mármol desde las canteras de la sierra hasta las fábricas. Las canteras de mármol de Macael son prácticamente las únicas canteras de Andalucia que a principios de siglo XX han sido capaces de crear a su alrededor una industria de transformación. Hasta 1905 los bloques extraidos en Macael se aserraban en 25 fábricas que tenían más de 70 telares. Este sector ha sido protagonista de una espectacular y exitosa transformación en los últimos años, aunque en la actualidad ha entrado en recesión.

Un importante producto minero del valle del Almanzora era la esteatita o jaboncillo de sastre, como era conocido el talco en la comarca. La esteatita era bajada a la estación en recuas de animales y en carros a Purchena, donde era molido en las fábricas correspondientes a Echeverría y Acosta, y Sociedad Española del Talcos, y desde alli transportada en ferrocarril hasta el puerto de Águilas, desde donde era embarcado sobre todo a Barcelona.

Otros productos mineros explotados en los municipios de Bayarque y Tíjola fueron el mercurio y el cobre, ambos minerales en el entorno de la Cueva de la Paloma. El mercurio comenzó a explotarse en 1845 para lo cual se instalaron pequeños hornos de destilación, pero dejaron de hacerlo por las dificultades en la extracción; posteriormente siguió explotándose aunque de forma ilegal en los hornos Gascue-Rodríguez y Bustamante, en Tíjola. Entre 1940 y 1970 se reanudó su explotación y se instaló un horno, pero aunque rentable, dada la calidad del mineral, las cantidades extraídas fueron exiguas y dejó de explotarse. En cuanto al cobre, también se explotó en el mismo entorno, donde existen bocaminas cegadas por hundimientos. Había restos de una casa almacén, de una fragua y habitaciones, al lado de la cueva y en la Loma. Posteriormente se explotó en la mina Las Cocotas, en Tíjola, aunque con cantidades muy escasas. El mineral extraído se comercializaba por la estación del ferrocarril de Tijola.

\section{Bibliografía}

CLEMENTE RUBIO, S. DE R. (2002) Viaje a Andalucia. "Historia natural del Reino de Granada" (1804-1809). Almería-Barcelona: GBG, 2002

GRIS MARTíNEZ, J. (2000) The Great Southern of Spain Railwai Company Limited, 1887-1936. Águilas: Asociación Cultural de Amigos del Ferrocarril "El Labradorcico" de Águilas, 2000

GUARDIOLA, R.; SIERRA, A. DE (1925) Hierros de Almería y Granada. Tomo I. Madrid: Memorias del Instituto Geológico de España, 1925

RUIZ BALLESTEROS, E. (1999) Cultura minera en Andalucía. Demofilo, Revista de Cultura Tradicional de Andalucia, n. ${ }^{\circ} 32$, 1999, pp. 9-37

TORREBLANCA MARTÍNEZ, J. (2010) Gustavo Gillman y la revitalización económica del Valle del Almanzora. En GRIMA CERVANTES, J.; GILLMAN MELLADO, J. R. Almería insólita. El legado fotográfico de Gustavo Gillman, 18891922. Mojácar: Arráez Editores, 2010, pp. 93-114 